\title{
2 Implementing EMI in medical education in Taiwan
}

\author{
Shun-hua Wei and Jonathon Hricko
}

\section{Introduction}

English-medium instruction (EMI) programs are rapidly being implemented in Taiwanese higher education. One primary goal in doing so is to internationalize higher education in Taiwan. However, the implementation of EMI in medical schools in Taiwan has lagged behind other disciplines. As a result, Taiwanese medical schools are at risk of missing out on the benefits of EMI in particular and internationalization more generally. This chapter aims to identify some of the challenges associated with implementing EMI in Taiwanese medical schools and to offer some guidelines that address those challenges.

In the course of doing so, we follow Chin and $\mathrm{Li}$ (Chapter 1) in emphasizing that "English" in EMI is the medium as opposed to the object of study, and that EMI ought to be implemented as part of a dual-track system in which EMI courses aim for content learning, while courses in English for specific purposes (ESP) and English for academic purposes (EAP) aim for language learning.

\section{Internationalization and EMI in Taiwanese higher education}

University internationalization is one of the main reasons why universities have implemented EMI programs. Like other Asian regions such as Singapore, South Korea, Malaysia, and Japan, Taiwan regards EMI as an effective means of driving university internationalization and has implemented EMI for a variety of academic subjects (Fenton-Smith et al., 2017). Chin and Li (Chapter 1) provide a useful summary of the current state of affairs regarding EMI in Taiwanese higher education. As they observe, the initiatives that the government of Taiwan introduced in 2002 resulted in a dramatic increase in the number of EMI courses and programs. As of 2019, there were about 66 EMI programs at the bachelor's level, 263 at the master's level, and 148 at the doctoral level (Taipei Economic \& Cultural Office in Thailand, 2019). A list of 260 EMI undergraduate and postgraduate programs (Taipei Economic \& Cultural Office in Thailand, 2019) reveals that $40.8 \%$ of these programs are 
offered in private universities while $59.2 \%$ are offered in public universities. However, as of 2019, EMI courses still accounted for less than $20 \%$ of the total courses offered in the four leading Taiwanese research-orientated universities, all of which are public universities (Zhong, 2019).

Taiwan's pursuit of university internationalization, and the resulting implementation of EMI, can be explained by a number of factors. First of all, Taiwan is a small island with a large population and relatively few natural resources. Internationalization is seen as an important means to foster and attract global talents and secure global resources to ensure Taiwan's continued growth and development. Second, internationalization is seen as an important means of enhancing the global competitiveness of Taiwanese universities. Third, an internationalized campus environment is viewed as beneficial insofar as it results in an environment in which local and international faculty, students, and staff use English as a lingua franca in order to exchange valuable knowledge and skills.

Although universities should ideally strive to create and maintain a positive environment that attracts international students and facilitates their interaction with local students, universities in Taiwan face a number of challenges in doing so. Some of these challenges result from the difficulties associated with teaching classes that include both local and international students (Huang, 2015). Universities must find ways to facilitate interaction among students that respect differences in educational needs, language proficiency, and cultural backgrounds. However, as Chin and $\mathrm{Li}$ (Chapter 1) observe, international students currently make up a relatively small percentage of the student body in Taiwanese higher education, and the vast majority of students enrolled in EMI courses are local students. As a result, they emphasize the importance of prioritizing the challenges that these local students face and providing them with the support that they need, which requires maintaining a role for local students' first language when implementing EMI.

Other challenges result from the resistance of faculty members to the implementation of EMI in Taiwanese higher education. In 2016, the president of National Chengchi University (NCCU) introduced a policy according to which newly hired teachers must be prepared to offer at least two EMI courses every semester. In response, Chien-San Feng, a professor at NCCU, wrote an open letter to the president in which he condemned this new policy ("New teachers increase English courses," 2016). The letter was subsequently signed by 154 faculty members at NCCU, and it induced a heated debate regarding the place of EMI within higher education in Taiwan. As a result of this controversy, universities have tended to adopt a policy according to which newly hired teachers are not required to offer EMI courses; but job applicants who are able to do so are given higher priority.

Addressing these challenges and concerns is a difficult task, and the development of satisfactory solutions will undoubtedly require a significant amount of work. In the course of working toward solutions, there are a number of points that higher education policymakers should keep in mind as 
they pursue university internationalization. First, internationalization does not simply amount to a group of people speaking English in a specific environment on campus. It must involve the flow, both within and across universities, of people who carry knowledge, skills, and values. Second, university internationalization should be viewed as an evolutionary process. It is important for policymakers to realize that time is needed to reshape a school's infrastructure and atmosphere. Third, fostering a positive environment for university internationalization provides a foundation for further development. A positive environment for university internationalization is one in which all stakeholders - local and international students, faculty, and staff - enjoy the benefits of networking and share the knowledge, skills, and other resources that result from it. Fourth, policymakers should recognize the important role that the English language plays in the process of internationalization and should be prepared to use it as an interface for communication. Fifth, the internationalization of higher education will inevitably have an impact on Taiwan, and it is helpful for policymakers to view this process as one that provides positive momentum to reshape Taiwanese universities. Policymakers should therefore set up strategic measures in order to minimize the negative effects and maximize the positive effects of university internationalization.

\section{EMI in Taiwanese medical education}

Today, there are 13 medical schools in Taiwan. ${ }^{1}$ Some of these schools are located within comprehensive universities while others are not. Students in medical schools in Taiwan are generally required to train for four years as undergraduate students. However, some specialists, such as medical doctors, dentists, pharmacists, and physical therapists, are required to train for six years. Taiwanese medical schools previously provided seven years of educational training, until reforms were instituted for six-year programs in order to bring Taiwanese medical education in line with international standards. Once medical students graduate, they must spend a further two years in hospital-based training. The first and second years of hospital-based training are referred to as postgraduate year one (PGY1) and postgraduate year two (PGY2), respectively.

The first four years of in-school medical education are organized in the following way. The first two years of in-school education are intended to encourage students to embrace a humane spirit. Therefore, many courses in this stage are in the humanities and social sciences, in fields such as literature, sociology, economics, and political science. The third and fourth years focus on fundamental sciences such as gross anatomy, histology, neuroanatomy, physiology, medical genetics, parasitology, and embryology.

The objectives of these courses are designed to help students lay a foundation for further studies in clinical medicine in PGY1 and PGY2. These studies in clinical medicine relate to both disease diagnosis and treatment. Clinical medicine associated with organ disease covers cardiovascular medicine, 
pulmonary medicine, nephrology, urology, oncology, neurology, and psychiatry; clinical medicine associated with disease diagnosis covers image diagnosis, pharmacology, and clinical skills.

Although there are a number of EMI programs devoted to medical education in Taiwan, the medical fields lag behind other fields of study when it comes to the implementation of EMI programs. On a list of 260 EMI undergraduate and postgraduate programs compiled in 2019 (Taipei Economic \& Cultural Office in Thailand, 2019), a total of $41(15.8 \%)$ are in engineering, 44 $(16.9 \%)$ are in business, and $45(17.3 \%)$ are in medicine and health. However, these numbers are slightly misleading because 24 of these medicine and health programs are offered at one private university; there are only 21 medicine and health programs at all other universities combined. A finer-grained analysis therefore suggests that, in general, the medical fields have struggled to keep up with other disciplines when it comes to the implementation of EMI programs.

This state of affairs may be explained by the specific requirements of medical education. Courses designed in medical disciplines must be consistent with Taiwan Medical Accreditation Council guidelines. Students must complete many challenging courses within only a few years. As a result, faculty and students are mostly concerned about learning outcomes, and there is little room to embed EMI in courses.

Both faculty and students have expressed misgivings about the implementation of EMI in Taiwan. These misgivings may be compounded by the strict requirements on medical education, which in turn may result in a lack of flexibility in developing EMI courses in medical schools. It must be admitted that these misgivings are legitimate concerns, and in order to implement EMI programs successfully, both in medical schools and more generally, these concerns need to be addressed.

Regarding the implementation of EMI in general, faculty in Taiwan have expressed a number of misgivings. Some faculty are concerned that EMI seems to require sacrificing course content (Huang, 2012). Because of the low English proficiency among some students, teachers worry that an EMI course cannot cover more than a fraction of the content that a traditional first-language course would cover. Faculty in Taiwan have also indicated that EMI courses have the effect of decreasing opportunities for class discussion and increasing various difficulties that teachers encounter in the classroom (Chow, 2018). In particular, faculty have indicated that using English to introduce abstract, complicated concepts to students is a source of frustration. Moreover, although EMI teachers are experts in the content that they teach, they are usually not experts in teaching English, and may not therefore be fully equipped to address the linguistic challenges that students face in the course of learning content via an unfamiliar language (Chin and $\mathrm{Li}$, Chapter 1). As a result, many faculty members in Taiwan believe that too much emphasis on EMI courses in higher education may result in weakening students' professional competence, and that the first language should therefore be the main communicative interface for disseminating content in Taiwanese higher education (Tseng, 2012). 
As to students' misgivings about the implementation of EMI in Taiwan, Chin and Li (Chapter 1) provide a useful summary of the difficulties faced, not just by Taiwanese students, but by Chinese-speaking students more generally. As they observe, even students with strong English skills may face difficulties when learning content via English, especially if they are used to discussing this content in Chinese. They also note that students with lower levels of English proficiency face even more challenges insofar as they are required to master unfamiliar academic content via an unfamiliar language.

The implementation of EMI in Taiwanese medical education is viewed as having both advantages and disadvantages. When it comes to the perceived disadvantages, it would be reasonable for medical students and faculty members in Taiwan to share the sorts of misgivings discussed above. When it comes to the perceived advantages, medicine and health programs taught in English in Taiwanese universities satisfy important educational needs insofar as they facilitate the transfer of knowledge and skills across international borders. After all, students and faculty tend to use English when participating in international conferences, workshops, and courses. The introduction of EMI into medical schools in Taiwan is therefore seen as both promising and challenging. However, the quality of EMI teaching and learning outcomes for Taiwanese medical education is still largely unknown. In order to implement EMI and assess these outcomes, more work needs to be done to address various challenges within the relatively inflexible curriculum of medical education in Taiwan. The remainder of this chapter constitutes a first step toward the completion of this work.

\section{Intended learning outcomes associated with introducing EMI into medical schools}

The implementation of EMI programs may affect, and ideally improve, the quality of medical training and knowledge construction when it comes to students' learning outcomes. When EMI courses are introduced into medical schools, students' learning quality and outcomes associated with their professional skills are among the first priorities. English is an essential means of knowledge acquisition and communication for medical students and professionals. In order to acquire the most accurate, up-to-date knowledge, both students and professionals are required to read the most recent literature in their field, which is published in English. English skills are thus important even for students who plan to practice locally. Extensive implementation of EMI courses could therefore improve students' learning quality, especially when they are constructing new knowledge in medical specialties.

Students' learning outcomes after undergoing medical education can be evaluated in terms of two categories: English competence and competence in medical specialties. Each category can be divided into four levels: Foundation, developing, proficient, and expert. Figure 2.1 depicts three possible outcomes regarding students' competence in medical specialties and English after 


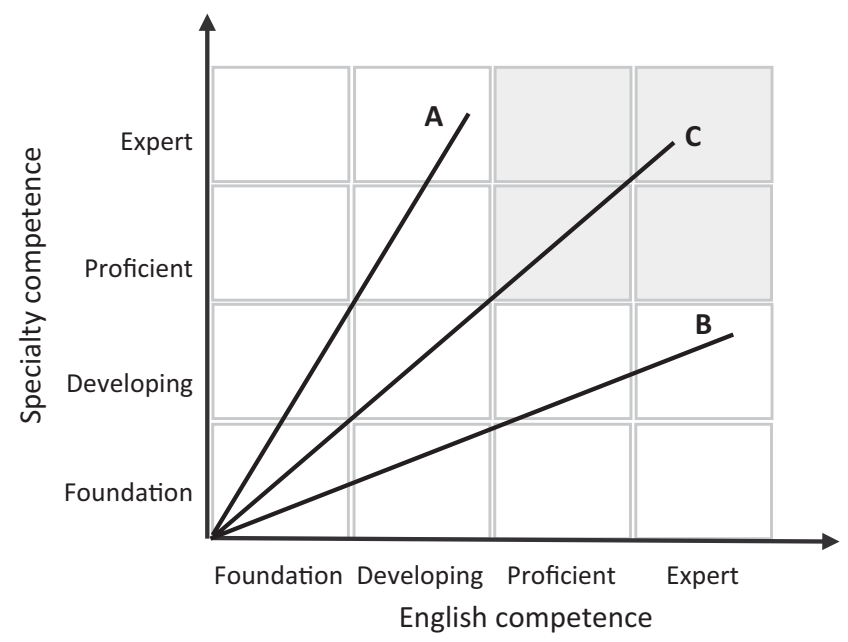

Figure 2.1 Students' competence in medical specialties and English after academic training.

undergoing medical training in a school environment. The horizontal axis in Figure 2.1 represents students' English competence and the vertical axis represents specialty competence.

Line $\mathrm{A}$ in this figure indicates that years of medical education have shaped students into experts in their medical specialties, but their English competence remains at the developing level. Although this is a hypothetical situation, it may to some extent reflect reality when students in Taiwan finish their training in medical school. There are several possible reasons for this. First, many English courses in medical schools still focus on general English, which does not satisfy professional requirements. Second, students are often able to satisfy their English course requirements within the first two years of study, and are not required to consistently take additional English courses throughout their undergraduate education. Third, schools may not provide adequate extracurricular resources for students to acquire and develop English skills, for example, workshops, symposiums, and speeches conducted in English. These factors may limit students' development of English ability.

Line B suggests that students have reached expert-level English competence, but their specialty competence remains at the developing level. Largescale introduction of EMI courses without strategic considerations to avoid sacrificing professional education may result in a situation in which students do not reach the desired level of specialty competence. Improvement of English language proficiency should not occur at the expense of professional studies. 
Line $\mathrm{C}$ is the ideal result of students' in-school training, as both their professional skills and English competence reach expert levels. Line-C students are not only able to practice medicine in domestic hospitals but are also able to actively participate in the global medical community. Such students are more likely to become successful bilingual experts. They are capable of using their first language to fulfill their duties in the medical context. Moreover, they can leverage their English skills in order to update their knowledge of medical science and technology.

What can higher education policymakers do to make the ideal line-C approach a reality? EMI is often taken to be a strategic approach to facilitate internationalization, and it must be undertaken through strategic measures. Strategic measures are needed because the blunt implementation of a policy of "all English, all the time" is both unrealistic and unwise. The first language should be preserved in some courses because it is the main conduit for medical practitioners to deliver medical content to the community. The first language should play a role in EMI courses as well. Administrators must ensure that English does not create a barrier to students' acquisition of knowledge associated with medical diagnosis and treatment.

In order to achieve line-C development for medical students, school policymakers should work out a feasible strategic plan for implementing EMI that takes into account various constraints, mobilizes various resources, and sets achievable goals. The two biggest constraints are arguably the small number of teachers qualified to teach EMI courses about the medical sciences and the inflexibility of the current medical school curriculum. As for resources, medical students in Taiwan tend to have significantly better English language skills than many of their peers in non-medical programs. Faculty members outside of medical schools who teach EMI courses and/or have advanced degrees from English-speaking countries are another resource. Regarding goals, although the ideal for line-C development is expertise in both specialty knowledge and English competence, it may be more reasonable for medical schools to set the goal of producing medical professionals with expertise in their field and a high level of proficiency (as opposed to expertise) in English. Moreover, policymakers should clearly state that the goal is for students to achieve a high level of proficiency in English as an academic lingua franca as opposed to a native speaker variety of English (Kirkpatrick, 2017). In other words, schools should aim to produce medical professionals who are qualified to use English as a tool for communicating with the global medical community.

\section{A strategic plan for implementing EMI}

A feasible strategic plan for implementing EMI in medical schools is one that meets the challenges imposed by various constraints and mobilizes the resources to which medical schools have access, with the goal of achieving line-C development for medical students. The issues here are, of course, 


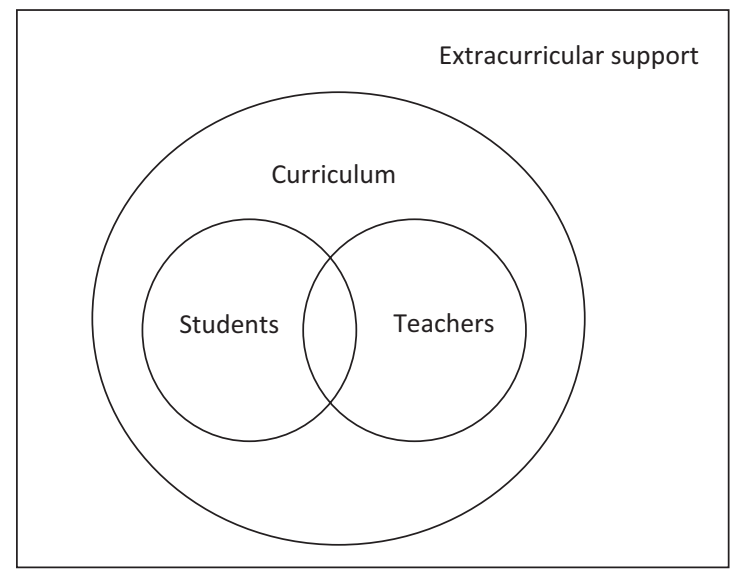

Figure 2.2 Four components in development of EMI courses.

complex, and it is useful for policymakers to consider these issues in terms of four essential components of EMI course development (which are depicted in Figure 2.2): Extracurricular support, curriculum design, students, and teachers. The successful implementation of EMI courses requires answers to the following questions regarding these four components: What are the objectives of the curriculum? What sorts of students will participate in the courses that make up the curriculum? What sorts of teachers will provide instruction for those courses? And what kind of extracurricular support is available? In the course of addressing these questions, policymakers can begin to identify various challenges regarding the implementation of EMI and develop strategic measures to address these challenges.

\section{Extracurricular support}

Ideally, EMI courses should take place within the context of a positive environment. A positive environment for learning content via English is an internationalized environment in which both local and international students naturally use English as a communicative interface for networking with each other. Fostering a positive environment is extremely useful for students and faculty engaging in EMI. Three pillars of fostering a positive environment are consulting with stakeholders, allocating EMI resources, and securing an adequate number of qualified EMI teachers. To cultivate a positive environment, schools may consider holding a variety of academic activities such as English speeches, workshops, and forums. These activities help students and faculty to naturally implement English in the university environment. It would also be encouraging to view local students naturally interacting with international students to conduct these activities. 
Importantly, international students should not be isolated, because doing so runs contrary to the objectives of university internationalization (Hou et al., 2013). Creating a positive environment for EMI should involve local and international students naturally blending and studying together in the same environment.

Unfortunately, these ideals are difficult to put into practice. Since medical schools aim to prepare students to practice locally in Taiwan, most medical students are local students. International students in medical schools tend to be native Chinese speakers from overseas who intend to practice in Taiwan. Hence, Taiwan's medical schools lack the sort of context that fosters English communication between local and international students. However, many of Taiwan's medical schools are located in universities that have a significant number of international students who are not native speakers of Chinese. These students take courses in English and, more generally, communicate primarily in English, which is often a second language for them. These universities thus have the resources to create a positive EMI context for medical schools, provided that they can offer opportunities for local medical students to blend in and study with international students in other programs. Courses that attract both local and international students may provide the sort of positive environment that is conducive to learning content via English in an internationalized environment. ${ }^{2}$

\section{Curriculum design}

Most medical schools in Taiwan require students to take at least six credit hours of English courses. Most of these required courses are general English courses, either at the fundamental or the advanced level (Table 2.1). Some schools also require medical English courses and offer various EMI courses, for example, courses on critical thinking and cross-cultural perspectives, that can be taken to satisfy English course requirements. While medical schools in Taiwan have settled on a similar set of policies regarding English course requirements, it is debatable whether satisfying these requirements will enable students to attain the level of English competence that they need in order to play a key role in the global medical community.

One challenge that medical schools in Taiwan face is providing an appropriate number of EMI courses for their students. Although many medical schools are engaging in EMI course development, the ideal number of EMI courses for the medical discipline is not obvious. Some courses provide excellent opportunities for students to learn academic content via English. Because the content and terminology of such courses are used universally, they can be considered good choices for EMI courses in medical schools. Some possible courses are shown in Table 2.2. The courses in Table 2.2 have been selected because they are the sorts of courses that are currently offered as part of the curriculum in medical schools in Taiwan, and because they are courses that benefit medical students regardless of their specialization and program 
Table 2.1 Students' entry level scores on the General Scholastic Ability Test (GSAT) and mandatory English courses and credit hours

\begin{tabular}{|c|c|c|c|}
\hline University & $\begin{array}{l}\text { GSAT } \\
\text { entry level }\end{array}$ & $\begin{array}{l}\text { Mandatory } \\
\text { credit hours }\end{array}$ & Mandatory courses \\
\hline NU1 & $7 \%$ & 6 & $\begin{array}{l}\text { Fundamental English I and II } \\
\text { Advanced English I and II }\end{array}$ \\
\hline NU2 & $7 \%$ & 6 & $\begin{array}{l}\text { Fundamental English I and II } \\
\text { Advanced English }\end{array}$ \\
\hline NU3 & $7 \%$ & 4 & General English I and II \\
\hline NU4 & $7 \%$ & 6 & $\begin{array}{l}\text { General English } \\
\text { Applying English } \\
\text { Medical purpose English } \\
\text { Advanced English }\end{array}$ \\
\hline PU1 & $7 \%$ & 6 & $\begin{array}{l}\text { Fundamental English I and II } \\
\text { Conversational English } \\
\text { English reading }\end{array}$ \\
\hline PU2 & $7 \%$ & 8 & $\begin{array}{l}\text { General English I and II } \\
\text { Advanced English } \\
\text { English listening and speaking }\end{array}$ \\
\hline PU3 & $7 \%$ & 6 & $\begin{array}{l}\text { Medical English } \\
\text { Fundamental English I and II } \\
\text { English writing }\end{array}$ \\
\hline PU4 & $7 \%$ & 6 & $\begin{array}{l}\text { General English } \\
\text { Listening and speaking English }\end{array}$ \\
\hline PU5 & $7 \%$ & 6 & $\begin{array}{l}\text { English I and II } \\
\text { Reading and writing English }\end{array}$ \\
\hline PU6 & $7 \%$ & 6 & $\begin{array}{l}\text { Listening and speaking English } \\
\text { Reading English }\end{array}$ \\
\hline PU7 & $7 \%$ & 6 & $\begin{array}{l}\text { Fundamental English } \\
\text { Advanced English }\end{array}$ \\
\hline PU8 & $7 \%$ & 4 & $\begin{array}{l}\text { Fundamental English, Speaking } \\
\text { English, English writing }\end{array}$ \\
\hline
\end{tabular}

Note: Medical schools located within national universities are coded NU1, NU2, and so on. Medical schools located within private universities or colleges are coded PU1, PU2, and so on.

Table 2.2 Recommended EMI courses in medical education

\begin{tabular}{lll}
\hline Liberal arts & Basic training & Specialized training \\
\hline - Philosophy & - Computer programming & - Healthcare policy \\
- Ethics & - Medical ethics & - Law and medicine \\
- History & - Public health & - Translational medicine \\
- Economics & - Biostatistics & - Evidence-based medicine \\
- Science and & - Information technology and & - Environmental health \\
technology & medicine & \\
\hline
\end{tabular}

Note: These courses include both general education courses (e.g., Philosophy) and core medical education courses (e.g., Public health). 
of study. These courses are therefore a natural starting point when it comes to medical schools engaging in EMI course development.

Policymakers should select courses that can potentially be developed into EMI courses without negatively impacting the way in which the medical school curriculum is currently structured in Taiwan. This selection ought to be based on two essential principles: (1) EMI course development should not result in significant changes to the current curriculum structure, and (2) EMI courses should primarily aim to use English as a tool for professional development. In other words, EMI courses should be inserted into the current curriculum in a way that ensures the integrity of the entire curriculum.

Medical schools should ensure that students have the English language skills that they need in order to thrive in EMI courses, and offer a sufficient number of EMI courses every semester so that students can take such courses at every stage of their education. Courses that focus primarily on improving language skills (EAP and ESP courses) should be offered alongside EMI courses in order to equip students with the language skills that they will need for their EMI courses. EMI courses offered in the first two years of study should be introductory-level courses that focus primarily on satisfying general education requirements. By the time students reach their third year of study, they will already be familiar with EMI and will be prepared for the more advanced EMI courses that provide the foundation of their medical education in the third and fourth years of study. These more advanced EMI courses will, in turn, prepare students for their fifth and sixth years of study, in which they will acquire more specialized, cutting-edge knowledge of their fields of study. These three levels of EMI courses are summarized in Table 2.3.

There is also the issue of whether EMI policy should require courses that are taught entirely in English, or whether there is a place for other languages in the teaching of EMI courses. In multilingual settings, teaching and learning are facilitated by the use of different languages, and it can therefore be beneficial to incorporate other languages within EMI courses (Chin and Li, Chapter 1; Kirkpatrick, 2017). In Taiwan in particular, a brief Chinese-language explanation of a difficult concept can equip students with

Table 2.3 Three levels of EMI courses

\begin{tabular}{|c|c|c|c|}
\hline Study year & $\begin{array}{l}\text { Area to embed } \\
\text { EMI courses }\end{array}$ & EMI course aims & Examples of courses \\
\hline $\begin{array}{r}\text { Undergraduate } \\
\text { years } 1 \text { and } 2\end{array}$ & Liberal arts & $\begin{array}{l}\text { General education } \\
\text { requirements }\end{array}$ & $\begin{array}{l}\text { History, Philosophy, } \\
\text { Economics }\end{array}$ \\
\hline $\begin{array}{r}\text { Undergraduate } \\
\text { years } 3 \text { and } 4\end{array}$ & Science & $\begin{array}{l}\text { Medical school core } \\
\text { requirements }\end{array}$ & $\begin{array}{l}\text { Biostatistics, } \\
\text { Healthcare policy, } \\
\text { Medical ethics }\end{array}$ \\
\hline $\begin{array}{r}\text { Undergraduate } \\
\text { years } 5 \text { and } 6\end{array}$ & Clinical study & $\begin{array}{l}\text { Medical research } \\
\text { and applications }\end{array}$ & Research seminars \\
\hline
\end{tabular}


the knowledge required to succeed in English-language classroom activities and assignments. There may also be a place for the use of Chinese in small group discussions among students, which can prepare the way for largegroup discussions in English. And it would be reasonable for lower-level EMI courses (i.e., EMI courses in the first two years of study) to provide more Chinese-language support. Moreover, it is important to emphasize, especially within the context of courses in medical ethics and applied communication skills in medical clinics, that the first language should be prioritized as much as possible when communicating with patients in the community. However, doing so may not always be possible given the linguistic diversity in Taiwan, where the first language may be Mandarin Chinese, Hokkien, Hakka, or one of a number of different indigenous languages. That said, English is rarely a first language. Teachers should therefore carefully consider whether a particular course is a good candidate for an EMI course, and also how to develop that course so that students can achieve the course objectives.

\section{Students}

Admission requirements vary among medical schools, but all are fairly stringent, and students admitted to medical schools tend to have better English language skills than many of their peers in non-medical programs. Universities assess an applicant's knowledge and competencies in terms of the General Scholastic Ability Test (GSAT), which is the university entrance exam in Taiwan. The GSAT includes a section that tests English language skills, and medical students' English scores are within the top 7\% of test takers (Table 2.1). As a result, medical students are competitive regarding their academic performance in English.

Medical schools set various criteria, based on standardized English tests, for the level of English competence that students should attain before graduation (Table 2.4). Students who demonstrate, via test scores, that they have satisfied the criteria are not required to take fundamental English courses. However, no students are required to take any of these standardized tests before graduation, and in practice, students' only English language requirement for graduation is the successful completion of a set number of English courses. In general, graduating students' English proficiency is not assessed in terms of any of the standardized English tests before graduation.

As a result, medical schools are faced with the following situation. The admission requirements ensure that admitted students possess English language skills that are significantly better than many of their peers in nonmedical programs. However, these are skills that can be lost over time, especially if students lack adequate opportunities to practice and improve these skills. As it stands, there is a serious risk that students will regress after taking the mandatory six credit hours of general English courses that are required for graduation. It is therefore possible that some graduating students have not attained the level of English competence specified in the criteria for 
Table 2.4 Criteria for students' English competence before graduation

\begin{tabular}{|c|c|c|c|c|c|c|c|c|}
\hline \multirow[t]{2}{*}{ University } & \multicolumn{3}{|c|}{ TOEFL } & \multirow[t]{2}{*}{ IELTS } & \multirow[t]{2}{*}{$G E P T$} & \multirow[t]{2}{*}{ TOEIC } & \multirow{2}{*}{$\begin{array}{l}\text { Cambridge English } \\
\text { Qualifications }\end{array}$} & \multirow[t]{2}{*}{ BULATS } \\
\hline & $I T P$ & $C B T$ & $I B T$ & & & & & \\
\hline NU1 & & & 100 & 7 & High- Intermediate & & FCE & \\
\hline NU2 & 550 & & 79 & 6 & & 750 & & \\
\hline NU3 & & & 83 & 6.5 & & 860 & FCE & 75 \\
\hline NU4 & 550 & & 80 & 6 & & 850 & & \\
\hline PU1 & & & 92 & 6.5 & High- Intermediate & 850 & & \\
\hline PU2 & 543 & & 87 & 5.5 & & & FCE, CAE, CPE & $\begin{array}{l}\text { ALTE } \\
\text { level } 3\end{array}$ \\
\hline PU3 & 500 & & 61 & 5 & High- Intermediate & 600 & & \\
\hline PU4 & 530 & 197 & 71 & 5.0 & High- Intermediate & 665 & FCE & \\
\hline PU5 & 500 & 173 & 61 & 5 & High- Intermediate & 600 & & \\
\hline PU6 & 565 & 227 & 87 & 6 & High- Intermediate & 800 & FCE & $\begin{array}{l}\text { ALTE } \\
\text { level } 3\end{array}$ \\
\hline PU7 & & & & & High- Intermediate & & & \\
\hline PU8 & 457 & 137 & 57 & 4 & High- Intermediate & 550 & & $\begin{array}{l}\text { ALTE } \\
\text { level } 3\end{array}$ \\
\hline
\end{tabular}

Note: Medical schools located within national universities are coded NU1, NU2, and so on. Medical schools located within private universities or colleges are coded PU1, PU2, and so on. 
graduating. Moreover, because students are only evaluated in terms of their general English skills, these measures may not reliably predict their level of ability in medical English communication and learning.

English courses should therefore be provided for students at different levels, and students should be encouraged to take at least one EMI course every semester in their program, so as to achieve consistent, incremental improvement that contributes to more effective learning. If medical students continuously take at least one EMI course per semester throughout their education, they will have an opportunity to maintain and build upon the strong foundation of English skills that they have when they are admitted to medical school. Table 2.3 provides information regarding EMI courses that focus on different subjects, that require different levels of English proficiency from students, and that can be offered at different stages of medical school education. While there are genuine concerns regarding students' ability to achieve intended learning outcomes in EMI courses, it may be possible to address these concerns by implementing the kind of sequence of courses presented in Table 2.3. After all, the aim of this sequence of courses is to make sure that lower-level EMI courses provide the foundation that students need in order to thrive in higher-level EMI courses.

\section{Teachers}

Undoubtedly, the quality of teaching and learning depends on the teacher. In general, teachers of EMI courses need to provide an environment in which students can construct knowledge and become active participants in the learning process. The teacher's mandate involves preparing detailed guidelines, organizing groups, helping students to select topics, guiding their research, helping them design effective presentations and use visual aids, providing feedback on writing assignments and exams, and evaluating the teaching process and revising it where appropriate. Teachers must also create opportunities for students to interact with them and with other learners. Teachers should serve as mediators who coach and encourage students to formulate their own understanding of the material.

This view of the teacher's mandate differs substantially from the view that teachers are knowledge dispensers, which is to some extent still present in higher education in Taiwan. Fenton-Smith et al. (2017) observe that much of the EMI-related research regarding Taiwan is premised on the idea that the teacher's primary activity is to deliver knowledge to students via monologic lectures. Indeed, in some EMI courses, students primarily listen to English lectures and read English textbooks, and have few opportunities to speak or write in English (Chang, 2010). However, it is not clear that the view that teachers are knowledge dispensers is the default view in Taiwanese higher education today. There are EMI teachers in Taiwan who reject this view and instead facilitate learning in a more interactive way that makes use of small-group work, presentations, and dialogue between students and teachers 
(Fenton-Smith et al., 2017). Hence, there is some reason to be optimistic that EMI teachers in Taiwan will embrace the view that teachers are mediators or coaches who facilitate learning as opposed to knowledge dispensers who only deliver monologic lectures.

To offer high-quality EMI courses in medical schools, teachers must be capable of both instructing students about medical knowledge and delivering it in English. The teachers who are most qualified to teach EMI courses in medical schools are therefore teachers who specialize in medical science or related sciences and have a high level of English language proficiency. Since the goal is to produce medical professionals who have expertise in their field and a high level of proficiency using English as a lingua franca to communicate with the global medical community, qualified EMI teachers should attain at least this level of English proficiency. Conversely, it is not necessary for EMI teachers to be native or near-native speakers of English. In short, teachers must be able to use English to effectively communicate medical information to students. To ensure their students' learning quality, EMI teachers should also be familiar with teaching skills and classroom management.

However, qualified teachers who are highly skilled in both English and medical specialties are difficult to find, and it is difficult to assess how many faculty members in Taiwan's medical schools possess the level of English competence required for teaching an effective EMI course. One possible indicator of the required level of English competence is graduate-level training (i.e., a master's or doctorate degree) from a university in an English-speaking country (e.g., the United Kingdom or the United States). Based on information collected from the websites of medical schools in Taiwan, faculty members who have either a master's degree or doctorate from an Englishspeaking country, on average, account for less than $10 \%$ of the faculty (Table 2.5). It is important to admit that having such a degree is neither a necessary nor a sufficient condition for the ability to teach an EMI course effectively. That said, the data presented in Table 2.5 do suggest that qualified teachers who are highly skilled in both English and medical specialties may be difficult to find in Taiwan.

One possible solution to this shortage of qualified EMI teachers is to offer courses that are co-taught by a medical professional and an English expert. By collaborating closely with one another, instructors can offer students an excellent opportunity to learn medical knowledge and improve their English language proficiency. Moreover, co-taught courses offer instructors an excellent opportunity to learn from each other. However, this solution may be more or less appropriate given the content of the course. For example, it may work better in a course on medical writing than it would in a course on biostatistics.

Another possible solution to this shortage is to offer more opportunities for professional development of EMI teachers. Indeed, there is a consensus in the literature on EMI in Taiwan that more opportunities for professional development are needed (Chang, 2010; Fenton-Smith et al., 2017; Hou et al., 2013; Huang, 2012). With enough opportunities and encouragement to undergo 
Table 2.5 Estimation of qualified EMI teachers in medical schools in Taiwan

\begin{tabular}{ll}
\hline University & $\%(M / N)$ \\
\hline NU1 & Not available \\
NU2 & $16.1 \%(16 / 99)$ \\
NU3 & Not available \\
NU4 & $4.2 \%(5 / 118)$ \\
PU1 & $3.7 \%(14 / 370)$ \\
PU2 & $7.6 \%(9 / 118)$ \\
PU3 & $17.8 \%(27 / 151)$ \\
PU4 & Not available \\
PU5 & $7.6 \%(11 / 144)$ \\
PU6 & $10.6 \%(10 / 94)$ \\
PU7 & $6.2 \%(9 / 143)$ \\
PU8 & $12.8 \%(10 / 78)$ \\
\hline
\end{tabular}

Note: $M$ represents the number of faculty members in the department of medicine who were awarded degrees from English-speaking countries. $N$ represents the total number of faculty members in the department of medicine. Medical schools located within national universities are coded NU1, NU2, and so on. Medical schools located within private universities or colleges are coded PU1, PU2, and so on. These data were collected from the official websites of the medical schools, which were accessed in April 2020.

professional development, a medical specialist with sufficient English language proficiency can become an effective EMI teacher.

A third possible solution to this shortage is for medical school policymakers to work with faculty outside of the medical school in order to implement EMI courses within the medical school curriculum. Most medical schools in Taiwan are located in comprehensive universities that have faculty members in other programs who teach EMI courses and/or have advanced degrees from English-speaking countries. Policymakers should include some of these faculty members on a task force for developing EMI courses for the medical school curriculum. Although these faculty members may lack medical expertise, they are still an important resource. Many of these faculty members are experts in fields such as biostatistics, computer programming, data science, and academic reading and writing. Courses in these areas provide the foundation for the specialized medical training that medical students receive at the more advanced stages of their education. Selection of such courses for EMI course development provides at least two advantages. First, students' learning is synchronized with global developments since the content and terminology is mainly transmitted via English. Non-EMI courses in the same areas may rely on (possibly inaccurate) translations of (possibly outdated) textbooks, in which case they are out of step with global developments. Second, these courses do not involve specialized medical knowledge and do not require instructors who have such knowledge. Hence, any negative impact to the current curriculum is to some extent minimized. 


\section{Support for EMI: English for academic reading, presentations, and writing}

In the course of implementing EMI programs in medical schools, policymakers should take steps to ensure that students are sufficiently prepared for EMI courses. It is often the case that EMI programs are implemented without paying sufficient attention to whether students have the level of English proficiency that will allow them to thrive in EMI courses (Chin \& Li, Chapter 1). Although medical schools typically require students to take general English courses at the fundamental and advanced levels, it is not clear whether these courses, on their own, are sufficient to provide students with the language skills they need for EMI courses. EMI courses should therefore be implemented alongside EAP and ESP courses that focus on teaching the English reading, writing, and presentation skills that will enable students to succeed in their EMI courses.

\section{English for academic reading}

The ability to read scientific reference materials in the original English is a core competence for medical specialists. Many university students in Taiwan are tempted to read English language scientific reference materials that have been translated into Chinese (Chang, 2010). This not only hampers students' development of English reading comprehension, it also adversely affects their development as medical specialists. Students may have especially poor learning outcomes if they use outdated textbooks in translation instead of newer English textbooks that contain updated scientific and technological knowledge.

In Taiwan, students have few opportunities to experience environments where English is the main language. However, reading English texts is a good opportunity for students to engage themselves in an English language context. Acquiring scientific knowledge by reading original English texts provides students with several advantages. First, it helps them build up their professional vocabulary. Second, it provides them with an understanding of how to apply this vocabulary. Third, it serves as an opportunity for them to develop their overall use of English in the realm of science and technology.

In addition to English reading skills, students must also be equipped with critical thinking skills. Being an active reader by asking questions and discerning the argument and logic of a text is essential in the development of critical thinking (Cullen et al., 2018).

Designing EAP and ESP courses in reading for academic and medical purposes will help students develop reading competence. These courses can be developed with four aspects in mind: Word comprehension, article comprehension, critical thinking, and summarizing ability. These courses are particularly helpful for first- and second-year medical school students, since they lay the foundation for further EMI studies in medical science. 


\section{English for academic presentations}

Today's rapid development of medical science and technology has caused scientists to largely adopt English for oral presentations so as to communicate with global peers at international conferences, workshops, symposiums, and meetings. Thus, to foster global talents in the coming years, administrators in higher education may consider implementing EAP and ESP courses devoted to teaching academic presentation skills.

By delivering academic presentations, students thereby improve both their knowledge and presentation skills. This process contains at least seven stages of learning for students. First, students must choose the topic they will research for their presentation. The second stage is document collection. Students must search for relevant articles through libraries and/or the Internet. The third stage is review and analysis. Students must read the collected articles critically and extract valuable information. Fourth, students must form arguments based on their personal knowledge and judgment. Fifth, when engaging in presentation design, they must outline concepts in a logical sequence and ultimately develop an effective means of communicating with other learners and teachers. Sixth, during their oral presentations, students must deliver their ideas, thoughts, knowledge, and beliefs in English to the audience. Seventh, after finishing their oral presentations, students must respond to the questions raised by the audience.

Students experiencing this learning process face many challenges in applying an English language mindset to transform their acquired knowledge and ultimately deliver an original argument in a formal setting. Although this is a very difficult task, it offers students a valuable opportunity for in-depth learning of how to use English as a means to acquire scientific knowledge and articulate an argument.

\section{English for academic writing}

New information is constantly emerging in the field of medicine by way of an ever-increasing number of research studies. This knowledge needs to be effectively communicated to different audiences, namely: Physicians, healthcare professionals, patients, and consumers.

Medical writing is a vital means of communicating scientific information. It includes the writing of documents such as disease- or drug-related educational and promotional literature, journal articles, healthcare websites, healthrelated magazines, and news articles (Sharma, 2010). As Sharma (2010) puts it, "The scientific information in these documents needs to be presented to suit the level of understanding of the target audience. ... The medical writer needs to have a clear understanding of the medical concepts and ideas, and be able to present the data and its interpretation in the way the target audience will understand." Scientific writing stresses communicative efficiency, so writers are encouraged to use plain English to deliver scientific information 
to their audience in a clear, concise, and accurate manner. Medical writing is a crucial competence for medical students prior to entering the medicine and healthcare sector.

Arguably, many students are still at the developing level of English medical writing before graduation, though data are needed to substantiate this claim. A number of reasons could explain the lack of proficiency of some students at this stage of their education. First, medical writing courses are not widely available in medical schools. Second, students may not be used to conveying their ideas and knowledge through English writing. Third, students may be incapable of using their critical writing skills to communicate medical science topics to their target audiences.

Critical writing is a process that involves using a range of writing skills to present an effective argument. This approach helps students to present their reasoning and evidence in a clear, well-structured manner in various formats (e.g., essays, reports, project proposals, and dissertations). Moreover, prior to engaging in critical writing, students must complete several necessary tasks to develop an informed argument. They must examine data from different angles, check the accuracy of information and the logic of their argument, confirm statistics and other empirical data, identify undeclared assumptions, and finally reach informed conclusions. These steps constitute a good approach for training students to engage in writing and helping them to develop critical thinking skills. Improving the quality of writing involves improving the quality of thought. Therefore, medical writing offers an excellent training opportunity for students to practice their critical thinking skills.

In order to understand how best to improve writing, a better understanding of how to read scientific articles is required. As Gopen and Swan (1990) put it, "Readers do not simply read; they interpret. Any piece of prose, no matter how short, may 'mean' in 10 (or more) different ways to 10 different readers." Therefore, writing with the reader in mind is the primary consideration. Consequently, it may be productive to teach academic reading skills alongside academic writing skills.

School administrators may consider establishing or further developing writing centers on campus to help students overcome barriers to English writing. They may also consider offering workshops or conferences to refine or improve faculty members' teaching skills in courses on medical writing.

\section{Conclusion}

While there are a number of difficult challenges associated with the implementation of EMI in Taiwanese medical schools, these challenges are not insurmountable. It is true that the medical school curriculum in Taiwan is relatively inflexible. But there is still room to implement EMI in a way that does not disrupt the existing curriculum. Medical schools should identify existing courses that are good candidates for EMI courses, and work on developing those courses. It is also true that it would be unwise to develop 
students' English language proficiency at the expense of their medical specialization. However, EMI need not be in conflict with the development of professional knowledge and skills, especially if English is viewed primarily as a tool for professional development. Another concern is that students lack the level of English proficiency necessary to succeed in EMI courses. While this is a real concern, it can be addressed by allowing a role for the Chinese language in EMI courses and by implementing EMI courses alongside EAP and ESP courses that teach the language skills that students need for their EMI courses. Although it may be difficult to find teachers who are qualified to teach EMI courses on medical science, there are ways to address this difficulty as well. Possible solutions include developing courses that are co-taught by a medical expert and a language expert, providing professional development for EMI teachers, and collaborating with qualified EMI teachers outside of medical schools who can teach EMI courses in the liberal arts and sciences. Hence, there is still room for EMI to play an important role in medical education in Taiwan. By consistently offering EMI courses every semester, medical schools can produce bilingual experts who can use their language skills not only to ensure that their knowledge of medical science and technology is up-to-date, but also to actively engage with the global medical community.

\section{Notes}

1 This chapter provides data regarding 12 of these medical schools. The medical school at I-Shou University began accepting students in 2019, and data regarding this school is not yet readily available on the school's website.

2 See Tables 2.2 and 2.3 for some examples of courses that may attract both local and international students.

\section{References}

Chang, Y.-Y. (2010). English-medium instruction for subject courses in tertiary education: Reactions from Taiwanese undergraduate students. Taiwan International ESP Journal, 2(1), 55-84. doi:10.6706/TIESPJ.2010.2.1.3

Chow, W.-C. E. (2018). English-medium instruction in higher education: A case study. Journal of Teaching Practice and Practical Innovation, 1(1), 155-191. doi:10.3966/ 261654492018030101004

Cullen, S., Fan, J., van der Brugge, E., \& Elga, A. (2018). Improving analytical reasoning and argument understanding: A quasi-experimental field study of argument visualization. npj Science of Learning, 3(1), 1-21. doi:10.1038/s41539-018-0038-5

Fenton-Smith, B., Stillwell, C., \& Dupuy, R. (2017). Professional development for EMI: Exploring Taiwanese lecturers' needs. In B. Fenton-Smith, P. Humphreys, \& I. Walkinshaw (Eds.), English medium instruction in higher education in Asia-Pacific (pp. 195-217). Cham, Switzerland: Springer. doi:10.1007/978-3-319-51976-0_11

Gopen, G. D. \& Swan, J. A. (1990). The science of scientific writing. American Scientist, 78(6), 550-558. 
Hou, A. Y. C., Morse, R., Chiang, C.-L., \& Chen, H.-J. (2013). Challenges to quality of English medium instruction degree programs in Taiwanese universities and the role of local accreditors: A perspective of non-English-speaking Asian country. Asia Pacific Education Review, 14, 359-370. doi:10.1007/s12564-013-9267-8

Huang, D.-F. (2015). Exploring and assessing effectiveness of English-medium instruction courses: The students' perspectives. Procedia - Social and Behavioral Sciences, 173, 71-78. doi:10.1016/j.sbspro.2015.02.033

Huang, Y.-P. (2012). Design and implementation of English-medium courses in higher education in Taiwan: A qualitative case study. English Teaching and Learning, 36(1), 1-51. doi:10.6330/ETL.2012.36.1.01

Kirkpatrick, A. (2017). The languages of higher education in East and Southeast Asia: Will EMI lead to Englishisation? In B. Fenton-Smith, P. Humphreys, \& I. Walkinshaw (Eds.), English medium instruction in higher education in Asia-Pacific (pp. 21-36). Cham, Switzerland: Springer. doi:10.1007/978-3-319-51976-0_2

Sharma, S. (2010). How to become a competent medical writer? Perspect Clin Res, 1(1), 33-37.

Taipei Economic \& Cultural Office in Thailand. (2019, January 15). Study in Taiwan manual. Retrieved from www.roc-taiwan.org/uploads/sites/89/2019/01/Study_in_ Taiwan_Manual_20190115.pdf

Tseng, H.-C. (2012). 國際化與全英語授課的迷思 [Myths of English-taught courses for university internationalization]. Taiwan Educational Review Monthly, 1(6), 39.

Zhong, L.-H. (2019, July 12).監院調查: 台成清交全英語授課未達2成 [Investigation by the Control Yuan: Whole English courses at National Taiwan University, National Cheng Kung University, National Chiao Tung University, and National Tsing Hua University are less than 20\%]. Liberty Times Net. Retrieved from www. news.ltn.com.tw/news/Taipei/breakingnews/2850581 [URL inactive]

(2016, March 21). 新師加重英文授課教授怒批政大校長「便宜行事」[New teachers increase English courses, professors angrily criticize school president for "doing things cheaply"]. Liberty Times Net. Retrieved from www.news.ltn.com.tw/news/ politics/breakingnews/1639227 